An ESRC Research Group

\title{
Capabilities, reproductive health and well-being
}

\author{
GPRG-WPS-005
}

\author{
Jocelyn DeJong
}

Global Poverty Research Group

Website: http://www.gprg.org/

The support of the Economic and Social Research Council (ESRC) is gratefully acknowledged. The work was part of the programme of the ESRC Global Poverty Research Group. 


\title{
Capabilities, Reproductive Health and Well-being
}

\section{GPRG-WPS-005}

\author{
Jocelyn DeJong*
}

\begin{abstract}
SUMMARY:
Lack of reproductive health constitutes a significant deficiency in well-being in developing countries, yet is often marginalised within development studies. This paper asks whether applying Amartya Sen's capabilities framework to reproductive health may provide one means of bridging this gap and advantages over prevailing approaches based on Disability Adjusted Life Years or reproductive rights. It draws on analysis of three reproductive health problems, namely obstetric fistulae, maternal mortality and female genital mutilation and argues that the capabilities approach offers an opportunity to address the social bases of health and one class of societal claims to social justice, but that there are methodological and other challenges to operationalising this approach.
\end{abstract}

\footnotetext{
* AUTHOR CONTACT DETAILS:

Institute for Development Policy and Management, University of Manchester, Harold Hankins Building, Oxford Road, M13 9QH, UK

Tel. 44-161-275-2800; Fax 44-161- 2738829

Email: Jocelyn.dejong@manchester.ac.uk or dejongjocelyn@yahoo.com

\section{ACKNOWLEDGEMENTS:}

Research for this paper was made possible by financial support from the Global Poverty Research Group funded by the Economic and Social Research Council. I am particularly grateful to John Toye for very useful comments on earlier drafts of this paper.
} 


\section{Introduction}

Lack of reproductive health constitutes a significant deprivation of well-being in developing countries and yet the field is not central to mainstream development policy. This paper seeks to examine the usefulness of the capabilities approach to an analysis of reproductive health in developing countries. It focuses its content on the development of three research questions, the first being primarily theoretical, the second more policy-orientated and the third centering on methodological approaches. With its direct focus on defining development as enhancing people's well-being, the capabilities framework has strong potential to reinforce efforts to advance reproductive health.

As elaborated initially by Amartya Sen (see Sen 1992, 1993, 1999) the capability approach represents a powerful critique of measurements of welfare based on utility. This approach draws on a liberal philosophical framework emphasising the importance of the well-being of the individual in terms of what he or she is able to do and become and the kind of life he or she is able to lead. In this view, individual capabilities are buttressed by so-called 'social arrangements' (e.g. Sen 1993) that either support or deny capabilities. Nussbaum (2000) has further developed the capabilities framework with a particular focus on women's capabilities in developing countries. She distinguishes between: 1) 'basic capabilities' generally innate from birth; 2) 'internal capabilities' which are developed states of the person; 3) 'combined capabilities' which require an appropriate political, economic and social environment 
for their exercise (italics my own) (Nussbaum 2000: 84-5). Using case-studies from the emerging field of reproductive health, then, the paper addresses the question: How can we address the social arrangements that are said to mediate individual capabilities? In particular, to what extent does the capabilities approach help us in analysing biases within society along political, cultural or other lines that lead to deprivation of capabilities?

Secondly, within the policy arena, does the capability approach help us in framing the concerns of reproductive health within the broader debates concerning development? The objective of such a dialogue would be, on the one hand, to accord greater prominence to the costs to development of deprivation in this field. On the other hand, one would hope it would illuminate the social bases of poor reproductive health and explore the relationships between poor outcomes in that sphere with other types of socio-economic disadvantage, a surprisingly under-researched area.

Thirdly, methodologically, what specific approaches to measuring reproductive health would address the above questions? The prevailing and highly influential approach to measuring the burden of disease in a population developed by the World Health Organization (WHO) and the World Bank uses so-called Disability Adjusted Life Years (or DALYs).

To approach these questions the paper will first briefly elaborate on the field of reproductive health as it has emerged over the last two decades. It will then introduce the concept of DALYs and how they have been used to measure the disease burden posed by poor reproductive health. The third section will provide some background 
on the concept of capabilities as developed by Sen and elaborated by Nussbaum (but very much influenced by the ideas of Rawls) before reviewing the usefulness of this approach for reproductive health and its distinctiveness from other approaches. The fourth section will be based on analyses of three sample reproductive health problems of particular relevance to the developing world, namely maternal mortality, obstetric fistulae and female genital mutilation (or cutting). It will examine the extent to which the capabilities framework is useful in analysing these, and if so what methodological approaches are most appropriate. The paper will conclude with some discussion of the policy implications of the capabilities approach as applied to reproductive health and questions for further research.

\section{The Emergence of Reproductive Health}

At the International Conference on Population and Development (ICPD) in 1994 in Cairo the governments of 180 nations endorsed a new approach to population policy centred on the concept of reproductive health. Conceptually, the term has come to describe an approach which sees women's health and well-being as important in their own right, not as a means towards the ends of fertility reduction or child health. In the interpretation of the ICPD, reproductive health addresses the broad determinants of women's and men's autonomy in making reproductive decisions and focuses on the [legal - SOCIAL] and ethical contexts in which these decisions are made. As a panel of the American National Academy of Sciences concluded, robust reproductive health implies that: 1) every sex act should be free of coercion and infection; 2) every pregnancy should be intended; and 3) every birth should be healthy (Tsui, Wasserheit and Haaga 1997: 13-14). The reality of human reproduction in developing countries 
is, of course, far from these goals, as is most visibly illustrated by the escalating HIV/AIDS epidemic.

Programmatically, the RH approach calls for an expansion of the scope (in terms of health problems addressed) of reproductive health services, including, but not limited to, family planning. It also entails broadening the constituencies to which reproductive health services are addressed to include not only women in the childbearing age but also those from adolescence to post-menopause. Reproductive health services that have been long been restricted to women should, it argues, open their doors to men. But the approach also makes a claim for inter-sectoral action to address gender inequality in social development more broadly.

Sen himself was in the forefront of those arguing that the alarmist perspectives on population growth that had dominated debates on the relationship between population and development in the 1960s and 1970s are not justified on empirical grounds. He was rightly concerned that they pose serious ethical problems in their programmatic consequences, encouraging a tendency towards coercion (see for example Sen 1994a; 1999). Moreover, Sen argued that the re-directing of resource flows towards family planning -- the logical extension of this alarmism -- detracts from encouraging broader social development that is the most effective and ethical way of reducing population growth. ${ }^{1}$ He underscores the potential 'unintended social costs' of such coercion in terms of loss of freedom and practices such as sex-selective abortion in countries such as China, where a prevailing preference for sons means that female foetuses are more likely to be aborted than male (Sen 1994a; Sen 1999). 
Sen's arguments, however, were joined by those of other academics as well as advocacy groups concerned about the abrogation of human rights witnessed in some population programmes, with the example of abusive programmes in India during the State of Emergency in 1975 and China widely cited as examples. A growing international women's movement since the 1970s had been arguing that women in the developing world often do not have reproductive autonomy in that their male partners and other household and community members influence their decisions, particularly where cultural norms value women primarily for their childbearing role $(G$. Sen, Germain and Chen 1994). Women's health advocates pointed out that women's lack of control over reproductive decisions limits their quality of life, poses a heavy health burden on them and ultimately constrains their participation in development processes (G. Sen 1994). They pushed for policy changes to make health services more responsive to women's needs and to treat the health consequences of reproduction, rather than being exclusively focused on lowering fertility, and they criticised the nature of many family planning programmes.

Thus the ground was laid for the shift that was observed in Cairo from an emphasis in international population policy on aggregate population growth to individual welfare and rights. Yet since 1994 implementation of this approach has faltered for a number of reasons including lack of political commitment, seeming contradictions between the exigencies of implementing reproductive health and health sector reform simultaneously, as well as funding constraints (DeJong 2000; Standing 2002). 


\section{Disability-Adjusted Life Years}

International discussion of public health priorities from a quite different perspective than the ICPD coincidentally ended up lending weight to the importance of reproductive health in developing countries. The publication in 1993 of the World Bank's World Development Report entitled Investing in Health ushered in a new method of comparing the burden of disease associated with different conditions. Devised by economists and epidemiologists, DALYs rely heavily on the techniques and assumptions of those academic disciplines. According to that World Development Report, they are a unit used for measuring both the global burden of disease and the effectiveness of health interventions, as indicated by reductions in the disease burden. DALYs are calculated as the present value of the future years of disability-free life that are lost as the result of the premature deaths or cases of disability occurring in a particular year. The use of DALYs is an attempt to move away from measuring health solely by a focus on mortality and to incorporate in a single summary measure the collective experience of disability over life times by discounting life-years to the present. As such, DALYs are a 'bad' to be avoided (Anand and Hanson 1998). Because of the claim that DALYs embody objectivity, comparability and authority, they have become the basic currency of international health policy debates.

The application of DALYs has been in some ways a boon to reproductive health advocates, in that there is now recognition that reproductive ill-health contributes five 
to 15 per cent of the global burden of disease at a minimum. Use of DALYs has also underscored the gender bias within reproductive health; whereas this figure represents three per cent of the total disease burden for men, the equivalent figure for women is 22 per cent (Abou Zahr and Vaughan 2000). Nevertheless, in its explicit rejection of the importance of socio-economic context and social relations - on the argument that this would undermine objectivity - this measure has many weaknesses with regards to analysing reproductive health. For, as will be argued further below, many

reproductive health problems are not only determined by social factors and norms, but their social consequences - such as stigma and shame - are heavily influenced by cultural context. Does the capabilities approach provide an alternative approach that overcomes some of these deficiencies?

\section{The Capabilities Approach and it Usefulness for Reproductive Health}

Sen presents his capabilities approach as the culmination of a critique elaborated over many years of prevailing utilitarian approaches to measuring welfare within development studies and economics. In developing these ideas, he was heavily influenced by the ideas of John Rawls as elaborated in his Theory of Justice of 1973. Rawls was highly critical of utilitarian approaches to measuring welfare, and in particular did not agree with the idea that some members of society should have to give up advantages for the greater good of society. He argued that social and economic inequalities should be 'arranged' so that the greatest benefit accrues to the least advantaged. In an approach analogous to (although clearly developed independently of) that of basic needs as a development strategy mooted in the 1970s, Rawls argued that each citizen should have access to what he called 'primary social 
goods,' ones that any rational person would choose and that this list would include, but not be limited to, income.

Sen, however, takes issue with the articulation of 'primary goods' in his argument that the yardstick should not be access to material 'goods' or income, but rather the wellbeing of people themselves. He also criticises Rawls for his lack of sufficient consideration of inter-personal differences in need (e.g. some may be handicapped in some way) and in the ability to convert commodities into welfare (Sen 1994b). These inter-personal differences, Sen (1994b) argues, are of critical importance for social policy. $^{2}$

Thus according to Sen's capabilities approach, policies should be evaluated not on the basis of their ability to satisfy utility or increase income, but to the extent that they enhance the capabilities of individuals and their ability to perform socially accepted functionings. For our purposes, the distinction between functionings and capabilites is critical. Functionings are the 'beings and doings' of a person whereas capabilities are 'the various combinations of [valued] functionings that a person can achieve. Capability is thus a set of vectors of functionings, reflecting the person's freedom to lead one type of life or another (Sen 1992: 40). In terms of reproductive health, therefore, capabilities would embrace such concepts as the ability to live through pregnancy and to a mature age without suffering premature mortality, whereas the equivalent measure of lack of functioning would be rates of maternal mortality. ${ }^{3}$

The distinction between capabilities and functionings is particularly important in its consideration of the role of human agency. Two people could be equally deprived in 
terms of functioning (such as being well-nourished for example), while one is a victim of famine and the other fasts for religious reasons, yet they do not have the same capability because the famine victim suffers from lack of choice. Similarly, in terms of reproductive health, an upper-class woman with recourse to abortion has quite different capabilities than a poor woman, and someone with HIV/AIDS in England has quite different capabilities from someone with HIV/AIDS living in Bangladesh. In all of these cases, Sen would use the capability approach to analyse the ways in which such differences are accounted for not only by differences in income, but also in terms of social arrangements and norms.

\section{Nussbaum's Approach to Capabilities}

Martha Nussbaum's work (2000) builds on Sen's ideas and represents an ambitious attempt to apply universalist principles of justice to gender equality in non-Western contexts in a manner which purports to be sensitive to local specificities. Nussbaum's main preoccupation is the pervasive discrimination against women in most of the developing world and the fact that 'considerations of justice for women have been disproportionately silenced in many debates about international development.' (Nussbaum 2000: 33) However, Nussbaum goes much further than Sen (who never makes a list of basic capabilities and uses them primarily for cross-country comparisons) $)^{4}$ by developing a list of capabilities on which she argues there can be cross-cultural consensus. These include life, health, bodily integrity, political participation, equal employment and secure property rights among others. 
In doing so, Nussbaum parts ways with many development practitioners in her critique both of cultural relativism in general and of the labelling of any effort to develop universalist notions of women's rights as cultural imperialism in particular. This tendency, she argues, ignores traditions of protest against gender injustice within cultural and religious traditions outside the West, and does not sufficiently account for dynamism within and interpenetration between cultures and societies in a globalised era. It is not, however, my purpose here to analyse the arguments for and against developing such a global list, but rather the usefulness of the general approach.

Nussbaum (2000) acknowledges that her notion of capabilities is very close to Rawls' listing of 'primary goods.' Nussbaum, however, follows Sen's advocacy of a shift from goods to people when measuring welfare, and thus refuses to acknowledge the importance of commodities in any form. Nevertheless, in recognition of feminist assertions that Rawls' conception of justice does not take sufficient account of people's needs for belonging and affection, Nussbaum (2000) addresses the 'family' to analyse what happens when principles of equality between the sexes may conflict with competing claims from relatives and in-laws. Nonetheless, she remains adamant that it is above all each individual's capabilities that need to be protected, as opposed to those of households or other social groups, as the communitarian critics of Rawls, such as Charles Taylor, would argue.

Nussbaum (2000) argues that there are advantages to applying capabilities over notions of rights to questions concerning women's status and well-being in developing countries. Before elaborating on these ideas, the following section outlines the basic features of the reproductive rights framework. 


\section{Reproductive Rights}

Based on a more generalised rights-based approaches to development, an alternative perspective that has been used by many reproductive health advocates - before and after the ICPD -- is one applying the notion of 'reproductive rights.' Scholars of reproductive rights, such as Rebecca Cook (1995) and Lynn Freedman (1999a), argue that a broad interpretation of reproductive rights is based on the same principles of social justice and dignity that Nussbaum attaches to the capabilities approach.

Narrowly defined, such rights are codified in international covenants and conventions, but also in international customary law. Thus applying their underlying principles provides a mechanism to hold not only states accountable to fulfilling obligations to reproductive health, but even non-state actors under their jurisdiction (Freedman 1999a). Freedman (1999b: 149) defines reproductive rights as:

'the constellations of legal and ethical principles that relate to an individual woman's ability to control what happens to her body and her person by protecting and respecting her ability to make and implement decisions about her reproduction and sexuality.'

She admits, however, that the language of rights has often been co-opted or manipulated to reinforce or to maintain the status quo and existing structures of power. Much of the resistance to internationally notions of reproductive rights has emerged because of their association with Western political traditions and the focus on individual civil and political rights, as opposed to social and economic rights. Moreover, there has been criticism of the implicit assumption that Western historical experience is somehow universally valid despite cultural differences. Yet reproductive health provides an example of a field where civil and political rights are inextricably 
linked to social and economic rights. For example, Petchesky and Judd's publication, which included in-depth case studies from seven different countries, illustrates the fact that common principles of dignity and social justice may be expressed in quite different forms across varied cultural contexts (Petchesky and Judd 1998). In Egypt, for example, women expressed a clear sense of multiple violations of their reproductive rights, but did not use the language of rights (El Dawla 2000).

Nussbaum argues that there is significant value-added to approaching questions of social justice within development from the vantage-point of capabilities as opposed to using the language of rights: 'Rights have been understood in many different ways, and difficult theoretical questions are frequently obscured by the use of rights language, which can give the illusion of agreement where there is deep philosophical disagreement' (Nussbaum 2000: 97). Among areas of disagreement among advocates of rights are whether the relevant unit of analysis is individuals or groups, and on the relationship between rights and duties. Perhaps the strongest argument she makes, however, is that rights may be understood quite differently across cultures whereas capabilities fulfil more fundamental and less contentious needs.

Therefore, despite the enshrining of reproductive rights in the language of international conventions, such as the ICPD, and international institutions, the implementation of reproductive rights and their definition across cultural context remains a fraught area. The heated debate at the ICPD itself between advocates of reproductive rights and the delegations of the Catholic and Muslim countries in particular concerning such contentious issues as abortion, sexual orientation and the reproductive health services for unmarried youth provides a clear example. While the 
reproductive rights and capabilities approaches share common basic principles - of social justice and dignity - arguably the capabilities approach shifts the emphasis to actual well-being, and may provide a less controversial approach to addressing sensitive questions relating to sexuality and reproduction -- as is discussed in the following section.

\section{Capabilities and Gender Inequalities}

The capabilities framework can be particularly useful for examining areas of gender inequity, although to the author's knowledge there has been no application to questions of reproductive health (with the exception of Harcourt 2001). As Robeyns (2002) has argued, while capabilities are ethically individualistic with their focus on individual well-being, they are not, contrary to the claims of many of their critics, ontologically so - that is, they allow for the importance of social relations, care and cultural norms. As Robeyns expresses: 'This is attractive for feminist research, because ethical individualism rejects the idea that women's well-being can be subsumed under wider entities such as the household or the community, while not denying the impact of care, social relations and interdependence.' (Robeyns 2002: 5). In this sense this framework is likely to be particularly helpful in analysing reproductive health, which inherently addresses relational processes of sexuality and reproduction while valuing the well-being of individual women. Moreover, this approach is able to address doings and beings in market as well as non-market settings (Robeyns 2002) - again a positive feature for analysing health outcomes which are not necessarily improved by addressing income, poverty or health care in isolation of broader contextual parameters. 
Moving way from income and utility as the yardstick can allow us to both reject instrumental approaches which subordinate women's health to the goals of fertility reduction or human capital, but also to see how poor reproductive health can apply across social classes. An interesting example of the latter point comes from the historical experience of maternal mortality in the UK. In the early twentieth century, upper class women were more prone to dying in childbirth because they tended both to rely on doctors who often interfered unnecessarily in childbirth and to be hospitalised when hospitals did not have adequate infection control. In contrast, the poorer classes relied on traditional midwives who had vast experience in dealing with complications and delivered at home (Loudon 2000).

Above all, however, using the capabilities approach to analyse reproductive health puts questions of social justice, ethics and distributional concerns at the centre of the debate and provides a normative framework explicitly based on a theory of justice rather than abstract exhortations. One would expect, therefore, that such an approach would provide the missing bridge between broader development debates and narrow health sector interventions based on biomedical models of health.

\section{Sen and Nussbaum on Health}

In both of their writings, Sen and Nussbaum allude to the fundamantal nature of health as a capability of intrinsic importance in its own right and instrumental to other capabilities. In a piece entitled 'Why Health Equity?' Sen argues that: 'Health equity may well be embedded in a broader framework of overall equity, but there are some 
special considerations related to health that need to come forcefully into the assessment of overall justice.' (Sen 2002: 663). He goes on to argue that health equity depends not only on the distribution of health-care, which is the central issue in much of the debate about inequality in health internationally, and that assessing questions of equity in health by nature requires a multidisciplinary approach. Sen typically takes issue with the 'procedural' approaches to justice of the so-called 'libertarians' whereby just procedures are the focus regardless of the outcomes (Sen 1999: 19). However, in the case of health as in other matters of social justice, he recognises that processes are important and that it is not only outcomes (functionings) that are of relevance. Thus discrimination in health care is an important issue no matter what the outcome (Sen 2002). To support this case, he argues that despite the fact that women in most populations tend to have a longer life expectancy than men, ${ }^{5}$ this does not mean that we should favour men in terms of access to health services that is, processes and not only outcomes are important.

As for Nussbaum, she includes two items of particular relevance to reproductive health on her list of critical capabilities. The first is 'bodily health' - being able to have good health, including reproductive health, to be adequately nourished; to have adequate shelter. The second is 'bodily integrity' -- being able to move freely from place to place; having one's bodily boundaries treated as sovereign, i.e. being able to be secure against assault, including sexual assault, child sexual abuse, and domestic violence; having opportunities for sexual satisfaction and for choices in matters of reproduction.' (Nussbaum 2000: 78) Given the fundamental nature of health capabilities, Nussbaum questions whether in this particular case, states should push 
for functioning not capability and undermine choice in certain aspects (Nussbaum 2000: 91).

Beyond underscoring the intrinsic and instrumental contribution of health capabilities in terms of social justice, neither Sen nor Nussbaum present an extensive discussion of how such capabilities may be approached methodologically, or indeed of the complexities of policy within this area. There tends to be the implicit assumption that access to health care is inevitably a 'good' without delving into the malfunctioning or systematic biases against women within particular health care processes. As Unterhalter (2002) notes of their work on education, more theorising of this area of social relations can reveal how education, for example, can also be a site of deprivation of capabilities. She gives the example of the use of education to promote the aims of the apartheid government in South Africa, or the current widespread sexual abuse of school-girls taking place in the same country to illustrate the disempowering nature of education in some contexts. Likewise, within the health and family planning field, certainly there is ample literature to indicate that women seeking health-care - and particularly poor women -- are often treated with disrespect and their needs are not always fully taken into account. In the worst case they are the victims of lack of ethical practice such as informed consent and even victims of abuse (e.g. G. Sen, Germain and Chen 1994; Kabakian-Khasholian et al 2000; Cottingham and Myntti 2002). Thus at issue is not only differential access to health-care but the very nature and processes of health-care itself. 


\section{Methodological questions concerning the application of capabilities to Reproductive Health}

The first methodological question one needs to confront in endeavouring to apply a capabilities framework to reproductive health is whether to address functioning or capability. Both Sen and Nussbaum argue convincingly that in terms of public policy and claims on the state, capability should be the starting point. A focus on capabilities as opposed to functionings protects sensitivities to cultural differences and both avoids paternalism and allows for pluralism. Thus an appropriate role for the state would not be forcing the person fasting for religious reasons to eat but in ensuring that everyone avoids starvation. As Nussbaum expresses: 'For political purposes, it is appropriate that we shoot for capabilities, and those alone. Citizens must be left free to determine their own course after that.' (Nussbaum 2000: 87).

Yet however superior the concept of capabilities may be on philosophical grounds, we are left with the methodological issue of how to disentangle the two. Sen does argue that since it is difficult to observe the capability set, "in practice one might have to settle often enough for relating well-being to the achieved - and observed functionings, rather than trying to bring in the capability set.' (1992: 52 quoted in Comim 2000: 9). In the case of reproductive health, however, we want to know not only the biological risks but the extent that the 'social arrangements' let women down and constrain their choices.

An interesting methodological approach to this conundrum was adopted by Burchardt (2002) in her analysis of unemployment of women in the UK relying on empirical 
data. She argues: 'It would be wrong to assume that someone is worse off because she is not working, while it is correct to assume that she is worse off if she lacks the capability for paid employment' (2002: 3). She took a two-prong approach whereby on the one hand, she assumed the capability exists but then tried to identify constraints. On the other hand, she assumed the capability for employment was not there and then analysed subjective preferences. As she notes, however, the first approach requires normative judgements about unobservable constraints, but the second is subject to the methodological constraints of 'adaptive preferences' 6 although it does address the unobservable constraints. The findings from this study are quite striking: nearly three-quarters of women who were not in paid work lacked employment capability, of whom only one-third would be picked up in official unemployment statistics. Such findings have immediate policy relevance, and Burchardt concludes that especially for women, employment capability is more relevant for policy than usual measures of unemployment (or functioning).

Burchardt justifies this approach by arguing that unlike being well-nourished, where if this is within the individual's capability set it is likely to be achieved, functioning and capability diverge in employment, and arguably particularly for women. That is, a woman may want to be employed but not achieve that state for a number of nonmarket reasons. I would argue, however, that even in health and nutrition the matter is not so straightforward, particularly in developing countries. Indeed one of the critiques of Sen's theory of entitlements and famines was prompted by empirical evidence that in famine situations certain people may 'choose to starve' in order to safeguard assets (de Waal 1990). However, it is extremely difficult to measure capability in health, and health indicators typically only tell us about functioning. This 
is particularly the case in reproductive health, as will be argued below, given the stigma and sensitivity associated with many health problems of this nature about which it is difficult to establish even functioning, let alone capability.

The relationship between capabilities and functionings is further complicated by the fact that there is a strong role of chance in determining health outcomes. That is, of two women of equal capability for good-health and equal access to quality healthcare, one may die of pregnancy-related mortality while the other with the same condition - for (as yet?) medically unexplained reasons --does not. Interestingly it was the influence of chance that convinced Rawls that he should not include health (at least initially) in his list of so-called 'primary goods.' That is, to Rawls, the state could not be expected to guarantee the health of its citizens. Nussbaum (2000) counters this argument by saying that states can, however, guarantee the social bases of health. The challenge, then, is to specify how these 'social bases of health' are linked to health outcomes which by nature calls for employing the techniques and data of epidemiology as well as the social sciences.

The second methodological question which is critical to consider is which functionings matter? According to Robeyns (2002) the capabilities approach by design does not tell us this, and yet when applying the approach to the concrete field of reproductive health there may be grounds on which the question must be broached. Robeyns (2000) further warns that the subjective judgements as well as the background of the researcher inevitably enter into these choices. She is particularly concerned that gender considerations may easily be ignored. That is, a welfare economist may not be concerned about gender differences in care responsibilities 
within the household and therefore not select these functionings for analysis (Robeyns 2000).

Prioritising capabilities would require applying some form of weighting which could also be used to address the third methodological question of how to aggregate capabilities? This is a general problem in the operationalisation of capabilities (Comim 2001). The capabilities approach itself does not tell us how capabilities should be aggregated into an overall well-being indicator (Robeyns 2002). But there is a specific problem which arguably applies particularly in health in that many capabilities are inter-dependent. Malnutrition insofar as it affects a young girl's development, for example, may be a risk factor for many subsequent reproductive health problems (e.g. obstetric fistulae described below) and this is where the epidemiological evidence as well as knowledge of social context must inform our choices of functionings. Can we then specify a hierarchy of capabilities?

Using the language of capabilities, DALY's represent an attempt to measure an actual burden or the extent of deprivation of 'functionings', and as such have been praised in many quarters for providing some level of aggregation. Yet the measure tells us little about capabilities which are the appropriate claim for social justice. How do we address reproductive health capabilities and not only functionings (or outcomes)? Ultimately understanding why individual and social differentials in capabilities produce varied outcomes is necessary if we are to judge the virtue of policies to improve reproductive health. 
An alternative approach has been to analyse all well-being indicators to assess where gender differentials in functionings are most marked. Saith and Harris-White (1999) attempt to do so just this and conclude that the under-10 female/male ratio is a suitable indicator for assessing gender differences in well-being. Thus where one would expect equality, deviation from the norm would indicate inequality. In reproductive health, however, it is known that biologically women bear a greater burden of ill-health independent of social constraints by virtue of the fact that only women get pregnant and are biologically more at risk of sexually transmitted infections (e.g. HIV/AIDS). However, at issue is whether 'social arrangements' exacerbate this biological inequality and how constraints on women's choices represent therefore an infringement of social justice. Thus distinguishing functionings and capabilities remains critical, as can be illustrated by considering the case of the following health problems.

\section{Reproductive Health Problems}

The following four reproductive health problems have been chosen as illustrative examples of the challenges of applying the capabilities framework to reproductive health. As the foregoing has hinted, the diversity of problems encompassed within the broad field of reproductive health calls for some disaggregation in order to investigate the implications of applying the capabilities framework to them. These examples represent a range along a number of dimensions, including a) the extent to which there has been policy attention to these concerns; b) the extent to which environmental factors play a role in their occurrence; and c) the importance of 'agency' in explaining their prevalence. All could be both objectively and subjectively 
defined as 'severe' both in their biological and socio-economic consequences for the women concerned.

\section{Maternal Mortality}

More than 1600 women die daily in the developing world for reasons connected to pregnancy, childbirth or its aftermath and this number constitutes 99 percent of all maternal deaths internationally. Indeed, maternal mortality is the indicator of wellbeing showing greatest discrepancy between the developed and developing world. Until 1987, the date of the first Safe Motherhood Conference, this fact was surprisingly not widely recognised within development policy. Since then the tragedy of avoidable maternal mortality has commanded increasing international attention, and the target of reducing maternal mortality by half now constitutes one of the Millennium Development Goals.

Maternal mortality is particularly apt for exploring the conceptual and methodological challenges of an application of the capabilities framework to reproductive health for a number of reasons. First of all, the role of chance (as discussed above in the context of Rawls) is critical. Maine (1999) argues that maternal health is quite unlike child health which could be said to operate under an additive model; that is a series of environmental deficiencies (poor water and sanitation, malnutrition etc.) add up to weaken resistance and produce high levels of infant and child mortality. With maternal mortality, however, more of a 'binomial model' (like flipping a coin) applies: a woman either does or does not develop a life-threatening complication during pregnancy and her survival depends on getting prompt, adequate emergency 
obstetric care. Exposure to the risk of maternal mortality occurs with every pregnancy, however, and therefore the risk is higher in countries with high fertility.

It is immediately clear, therefore, that maternal mortality is an event which can occur across social classes (as the example from the historical experience of the UK illustrates). However, once the chance, and relatively rare (even in developing countries with higher rates of maternal mortality) event occurs, the 'social arrangements' are critical which allow or impede a response to a potential crisis. These include the multiple social constraints on accessing available care, from the responses of partners, families and communities, to availing and being able to afford transportation even before the health-care system is reached.

Within public health, prevailing interventions to address maternal mortality have focused to a large extent on providing essential obstetric care. Over time, however, there has been increasing recognition within public health that maternal mortality provides a test for the entire health-care system in terms of how well it is able to discriminate and detect those women at high risk and act promptly to treat them. Thus issues of overall quality and management of health-care play a central role. In a national study of maternal mortality in Egypt, for example, over 50 per cent of the 'avoidable factors' leading to maternal deaths were due to medical mismanagement (Egyptian Ministry of Health 1993). These findings then prompt broader questions concerning the implications of overcrowding in medical schools, the poor quality of medical education and poor regulation by governmental powers - issues which, in Egypt, transcend the remit of the Ministry of Health. 
The legal context provides another important parameter for maternal mortality particularly because of the contribution of unsafe abortion to maternal deaths. It is estimated that unsafe abortion accounts for 13 per cent of maternal deaths (but less than one per cent in developed countries) (Maine 1999). The real legal context may be even more relevant, in terms of how social and religious norms influence behaviour. Thus religious norms are particularly influential in Catholic and Islamic countries where public policy has tended to make abortion illegal. ${ }^{7}$

Despite an appropriate focus on health-care and the legal context, however, there has been surprisingly little research on the link between socio-economic disadvantage and maternal mortality. ${ }^{8}$ That is, neither socio-economic risk factors nor the socioeconomic consequences of maternal deaths have been well-documented. This is in contrast to, for example, the field of HIV/AIDS where there has been significant research on the implications for families and orphans of a parent or both parents dying of HIV/AIDS. Borghi and colleagues (2003) found that in Benin, for example, in the cases of severe obstetric complications of a mother within a household, costs incurred reached 34 per cent of annual household cash expenditure. Thus economic burden may be one of many reasons why women do not get access to health-care when complications arise. The longer term consequences on children and households of maternal death, in terms of education, economic prospects and both physical and psychological well-being are virtually unknown, partly because they have not been prioritised within development policy. The prevailing DALY approach, for example, in its focus on the suffering of individuals, does not take into consideration this burden on households or communities of maternal mortality or indeed of any other health condition. 
Conversely, there has been little research addressing the question of how poverty may exacerbate risk to critical reproductive health problems such as maternal mortality. Graham et al. (2004) in a study based on analysis of eleven nationally representative Demographic and Health surveys found that there are significant associations between women's poverty status and their survival. In Indonesia, for example, approximately a third of maternal deaths occurred among women from the poorest quintile. The mechanisms through which this association acts, however, needs much further research. It is not clear, for example, whether the actual risk of reproductive complication is higher among the poor, or whether the likelihood of treatment is lower. As Graham and colleagues argue, without taking into account such intranational inequalities, development targets such as the Millennium Development Goals which focus on reducing national averages may miss the key point. Moreover, the DALY approach - in its focus on aggregating individual well-being - tells us little about such inequalities.

Thus, in this case, the research base to address the 'social bases of health' which Nussbaum advocates should be the claim on the state (in countering Rawls' assertion that states cannot guarantee the health of their citizens) is relatively weak; that is the level of knowledge about which 'social bases' are pre-eminent is lacking. While Sen (1989) himself has addressed the issue of women's 'survival as a development problem' this has been in the context of the so-called 'missing women' in India. This term has been used to describe the women not accounted for if one were to apply the expected sex ratio to the Indian population, and who Sen and others argue have been 
victims of systemic disadvantage in terms of nutrition and health-care (see for example Sen 1999).

Epidemiologically, determination of maternal mortality ratios (calculated as the ratio of maternal deaths to live births) in a population requires large-scale surveys since the event is relatively rare. A particular innovation was the introduction of the 'sisterhood method' (see for example Graham and Campbell 1992) in which live sisters of women who had died are interviewed to investigate circumstances of death. Typically such data is then referred to medical researchers to ascertain the cause of death and whether it was indeed maternal or not. Generally such surveys have not been used to generate information about socio-economic circumstances or social relations relevant to the maternal death in order to make analyses of the role of social class, region of residence or other factors. Such large-scale approaches need to be combined with much more micro-level and qualitative social science research to explore the social context and characteristics of individuals who experience life-threatening complications or subsequently die of them. Qualitative local studies at the community and household levels could start to address the true social bases of health and health care processes which population-level statistics, although critical, do not capture.

A potentially useful approach for a case control study would be to compare the response to the case of a woman who dies a maternal death with what have been called 'near misses" ${ }^{9}$ or women who suffer from life-threatening complications but do not subsequently die. Were such women 'saved by the system' in the sense that either the health-care system or social circumstances and relations were such as to prevent the maternal death? That is, were there characteristics of the social response to their 
condition or of the quality of health-care they received that increased their chances of survival? It is only when such types of research have been conducted that we can start to address capabilities to achieve a healthy pregnancy and delivery without suffering from premature mortality. Only then could we make inter-personal comparisons of capabilities and thus perhaps inform public policies in ways that might prevent this tragedy from occurring.

\section{Obstetric Fistulae}

Obstetric fistulae, ${ }^{10}$ a health problem which leaves women permanently incontinent, has been even less researched than maternal mortality, although both share some common risk factors, particularly prolonged and obstructed labour and lack of access to adequate obstetric care. As such it is a classic example of the 'measurement trap' (Graham and Campbell 1992) in that lack of political commitment to reproductive health in turn leads to lack of available data, leaving a vacuum in terms of trying to stimulate greater political commitment. Although long discussed among obstetricians and gynaecologists, fistulae occupy no central place in development policy debates.

There is extremely limited research on the issue, despite its severity, and data on its incidence is almost non-existent (Bangser et al. 1999; Donnay and Weil 2004). It has been reported, however, in Asia and throughout Sub-Saharan Africa (particularly Sudan, Nigeria, Tanzania and Ethiopia) as well as in Yemen. In 1989, WHO estimated that approximately 2 million girls and women worldwide suffered from the condition and that there were approximately 50,000 to 100,000 new cases globally each year (Donnay and Weil 2004). The limited research and anecdotal evidence from 
health-care professionals indicates that girls and women at risk of obstetric fistulae are often malnourished, short in stature with small pelvises, come from extremely poor families and have difficulty accessing transport and health-care during an obstetric emergency. Typically the women experiencing this condition are young, having married early.

Once fistulae of either type occur, they are very difficult medically to repair. The operation requires highly skilled surgeons and thus being very expensive. In some contexts, the expense of this complex and time-consuming operation means that for most poor women it is not a possibility (Donnay and Weil 2004). Research from India suggests that some women had been living with the condition for over 20 years before it was repaired (Bangser 1999). Thus, while the woman with obstetric fistulae escapes mortality she suffers from a severe, debilitating condition with severe socio-economic consequences often over a prolonged period, if not her whole life. Yet again, these severe socio-economic consequences are left out of DALY calculations which are restricted to the reduced physical functioning of individuals.

The severe stigma attached to this condition means invariably that such women face public shame, social exclusion and in many cases their marital and family relations break down and they lose their source of livelihoods. In almost every case the foetus dies as well, leaving the woman with the added stigma of childlessness if it is her first child. In Nigeria, studies have found that 'Women with VVF often work alone, eat alone, use their own plates and utensils to eat and are not allowed to cook for anyone else. In some cases they must live on the streets and beg.' (Bangser et al. 1999: 158). 
In terms of the capabilities, then, there is little data on the extent of the lack of functioning relating to obstetric fistulae. Virtually no social science research has been conducted on this condition and its consequences for the women, their relations or their communities. Like for maternal mortality as a functioning, the relevant capabilities in this case include being able to live safely through pregnancy and delivery but being well-nourished is critical. Autonomy to marry at an age when women are physically mature is clearly also a relevant capability. Yet once women are afflicted by this condition, access to appropriate and affordable care is central.

It is immediately clear, however, that trying to research capabilities relating to such stigmatised health conditions confronts enormous methodological challenges. It calls for local-level anthropological methods to reach those afflicted, who tend to be socially marginalised and whose conditions are often left out of official statistics. Such observational approaches would also elucidate the health-care processes which facilitate or hamper these women's capabilities.

\section{Female Genital Mutilation (or Cutting)}

In contrast to the problem of obstetetric fistulae, female genital mutilation (or FGM) ${ }^{11}$ as it has become known, is one of the central advocacy points of the growing reproductive health movement internationally. Indeed, FGM is perhaps the mostly frequently cited example used by universalists in their critiques of cultural relativism. Thus Nussbaum (2000) pays more attention to this particular reproductive health concern than any other. 
Since FGM often occurs in unhygienic settings, the risk of infection and potential later complication is high. The practice has been reported in more than 30 countries in Africa, but it also occurs in the Middle East (in Egypt, Sudan and Yemen) as well as to a much more limited extent in Asia. It is estimated to affect some two million girls every year ranging in age from infancy to adolescence (Tsui, Wasserheit and Haaga 1997).

Over the last ten years, the research-base on this practice has increased considerably and there now exist large-scale nationally representative data on many countries through the Demographic and Health Surveys. These have enabled analyses to be made regarding the potential role of education, changing patterns over time and differences in the practice according to such factors as region and social class. Qualitative research has also revealed complex motivations and attitudes (of parents) underlying the practice, although to the author's knowledge no research has been conducted on the attitudes of young girls to the practice. Large-scale data in Egypt, for example, has revealed the potential role of religion on the practice, in the context of a growing politicisation of religion in that country, with a growing number of respondents claiming that the motivation for the practice is religious. ${ }^{12}$

From a capabilities perspective this is a particularly complex problem particularly in relation to agency, not least because the decision to circumcise is taken by adults and perpetrated on children who do not have the opportunity of giving their informed consent. Recent qualitative research from Egypt has shown that in a context of economic deterioration, the marriageability of daughters is a prime consideration motivating mothers to have their daughters circumcised (El Dawla 2000). This 
research has revealed the complex trade-offs women may be making in sacrificing reproductive autonomy and bodily integrity to what they hope will bring greater economic security and arguably long-term well-being. That is, achieving greater economic capabilities may be overriding promoting capabilities to achieve reproductive and sexual well-being. There are also signs that increasingly private medical doctors are the main health providers carrying out this practice, reminding us yet again that health-care itself can be the site of deprivation of capabilities.

Nussbaum makes the assumption that all women who are circumcised are deprived of the capability of sexual expression, an assertion that might be challenged by Egyptian women in a country where 95 per cent of women are circumcised. Much more research is needed on the socio-economic and psychological consequences of this practice, however. Qualitative methods which would explore the motivations of parents in circumcising their daughters, as well as their interpretations of religious and social norms that sanction the practice, are critical.

Ultimately then, this returns us to the more theoretical questions concerning the limits of universalism as opposed to the need to engage the communitarian debates on justice which both Nussbaum and Rawls reject. Authors such as Gore (1997) have argued that although the capabilities approach cannot be accused of being morally individualistic, it does not go far enough in incorporating the intrinsic importance of institutional contexts and social norms. 


\section{Methodological Problems in Applying Capabilities to Reproductive Health}

As is evident from the foregoing discussion, all of the above illustrative reproductive health problems need to be analysed using different methodologies, and require different policy approaches. There are, however, some underlying commonalities. For example, shared by all of them, with the possible exception of maternal mortality, is the stigma and cultural sensitivity often associated with these health problems, which renders them very private and therefore seemingly invisible. In this sense, even functioning, let alone capability, is difficult to measure, and lack of political commitment has reinforced this methodological challenge in a vicious cycle whereby lack of data feeds policy silence.

While the DALYs approach does represent one attempt to capture the burden of disease independent of advocacy and special interest pleading, in the case of each of the above problems it misses a great deal. Part of this deficiency is due to informational constraints. The accuracy of DALY calculations depends on available epidemiological data and across the spectrum of reproductive health conditions these have tended to be under-reported (Sadana 2000). However, there may be more fundamental problems with the DALY approach as applied to reproductive health (Hanson 2002; Allotey 2002). Most importantly, in its intentional omission of context, it fails to consider the differential impact and socio-economic consequences of these conditions on women in different life-circumstances. A more or less stigmatising or negative social response in different settings for example -- may meet the same condition - such as infertility. As Reidpath and colleagues argue, when blindness in the UK and blindness in Niger are given the same disability weight, ${ }^{13}$ in 
spite of a context in the UK which makes disability less severe than in Niger, the social determinants of the impact of disease are ignored; the effect is thus to underestimate the burden associated with morbidity in disadvantaged populations and overestimate that in advantaged populations (Reidpath et al. 2003). Moreover, as Abou Zahr and Vaughan (2000) note, in its focus on individual suffering, the socioeconomic and psychological burden of these conditions falling on households and communities (as in the case of maternal mortality or HIV/AIDS) is excluded from analysis.

An example of an innovative multidisciplinary study in Egypt (Khattab et al. 1999) illustrates this methodological conundrum well. After two years of anthropological fieldwork in a low-income community of Giza governorate outside Cairo researchers interviewed women about their experience of reproductive illness. At the same time, doctors from the team trained the staff at the local government health services to improve their screening of reproductive tract infections and other reproductive health problems (when hitherto such clinics had mainly catered to providing family planning or pregnancy services). Members of the study team then asked if the women wanted clinical exams at the local clinic and in many cases where the women were reluctant, offered to accompany them to the health services. The results of the combined survey of women in their homes and clinical exams were striking: over 50 per cent of the women had reproductive tract infections (which can lead to infertility and enhance the spread of sexually transmitted disease) but none of these women had previously complained of these conditions to the local health services. Thus measuring functioning is difficult enough, before one begins to analyse capability in a context of a pervasive 'culture of silence' about women's health. The insights provided by this 
study were arguably only possible because anthropological or sociological methodologies to elicit subjective perceptions of well-being were complemented by the 'hard evidence' of clinical examination.

\section{Conclusion}

This paper has argued that using the capabilities approach to analyse reproductive health can be extremely useful in its focus on individual well-being while also taking into consideration relational processes of sexuality and reproduction. It shares with reproductive rights an underlying concern with social justice and human dignity, but it may be less controversial as an approach and less associated with Western political traditions and experience in the minds of many in the South, and arguably more directly linked to well-being. As we have also seen, locating reproductive health within a capabilities approach also has advantages over the prevailing use of DALYs, which has nevertheless accorded significant weight to the disease burden associated with reproductive health, particularly for women. It is arguably the combination of the use of DALYs and an increasingly vocal lobby of reproductive health advocates at the international level that contributed to making at least one reproductive health problem, maternal mortality, a subject of the Millennium Development Goals. Capabilities nevertheless provide distinct advantages over DALYs in that firstly, they provide more room for an explicit consideration of the social context and consequences of poor reproductive health. Secondly, the framework underscores the connection between the latter and social inequalities and deprivation, a subject that, as has been argued here, has not been adequately researched. 
Above all, since reproductive health advocates typically share the focus on social justice - and in particular a concern with gender inequalities -- embodied within the capabilities approach, their adoption of this framework would allow them to engage with mainstream development practitioners without having to succumb to the utilitarian perspectives that promote family planning in order to enhance development as defined by the satisfaction of preferences or to human capital approaches which see investment in education and health as a means of accelerating economic growth. If development is defined as enhancing well-being then efforts to promote reproductive health are inherent to that objective.

Yet if we follow Sen and Nussbaum and argue that capabilities, not actual functionings, are the appropriate claim for social justice, then there remain many methodological challenges in addressing the cultural, religious and ultimately political biases in society contributing to the widespread lack of capabilities to achieve reproductive health in the South. While both Sen and Nussbaum acknowledge such biases, the ultimate focus of capabilities is on the individual; even if buttressed by a concern with 'social arrangements,' this does not provide a clear path for addressing the social context of reproductive health methodologically. What is clear is that far from being a technical and narrow biomedical concern, reproductive health is a field influenced by a complexity of social factors and social relations that require a multidisciplinary approach if they are to be adequately understood. Aggregate population statistics are critical, but they must be complemented by more localised qualitative studies that illuminate motivations, behaviours and health-care processes as well as the social norms that stigmatise and obscure some of the most important reproductive health problems that blight the lives of women in developing countries. 
${ }^{1}$ Amartya Sen's lecture during the Preparatory Committee for the ICPD at the UN in New York, April 28, 1994 was arranged by the 'Eminent Citizens' Committee for Cairo '94' and was later published as Sen 1994.

2 In this context, Sen (1994: 334) notes that "The case of the pregnant woman is quite different - this is exercise of a special ability rather than the existence of a disability, but she too has extra needs related to the act of procreation."

${ }^{3}$ Maternal mortality is officially defined as deaths to women in pregnancy, during childbirth or during the 40 days following delivery.

${ }^{4}$ Sen's refusal to espouse a list is primarily due to his respect for democratic process and the danger of paternalism. According to Robeyns, Sen "advocates equality of capability, but does not defend one particular aggregative principle" (Robeyns 2000 FN 4) and in this sense, his approach to capabilities is not a full theory of justice. ${ }^{5}$ In separate work, Sen has singled out exceptions to this ratio such as China and India with their "missing women" where the ratio of women to men is less than 1 . He argues this is due to systematic biases against girls and women in terms of health-care and nutrition.

${ }^{6}$ Sen and Rawls among others have written about how chronic disadvantage shapes preferences as one of the main arguments against utilitarian approaches to measuring welfare. In the case of women's employment, for example, a woman interviewed in a government survey may claim she is not looking for work merely because she lacks confidence in her own employability.

${ }^{8}$ Graham et al. 2004; Drs. Oona Campbell and Veronique Filippi, London School of Hygiene and Tropical Medicine, personal communication, February 2003.

${ }^{9}$ For further detail on the public health use of near misses, see Filippi 1998

${ }^{10}$ Vesico-vaginal fistulae (VVF) represent a health problem which occurs when a hole develops between the vagina and bladder of a pregnant woman during prolonged and obstructed labour. In some cases the fistulae develop between the rectum and the vagina causing recto-vaginal fistulae.

${ }^{11}$ Female genital mutilation has been classified by the World Health Organization into four types ranging in severity from excision of the clitoris to "infibulation," whereby the labia majora are sewn together, leaving only a small hole.

12 Again, the Islamic position on the practice of female genital mutilation is beyond the scope of this paper. Certainly however there is nothing in the Qur'an to condone the practice and it is widely perceived to be against it. In Egypt, however, there have been conflicting statements on the part of the religious establishment in a context of a growing politicisation of religion in that country.

${ }^{13}$ In the calculation of the DALY, each health condition is assigned a disability weight ranging from 0 (health condition is equivalent to full health) to 1 (equivalent to death).

\section{References}

Abou Zahr, C. and Vaughan, P. (2000) "Assessing the burden of sexual and reproductive ill-heath: questions regarding the use of disability-adjusted life years" Bulletin of the World Health Organization V. 78, I. 5, p. 655- [check page nos.] 
Allotey, P. and Reidpath, D. (2002) "Objectivity in Priority Setting Tools: Context and the DALY" Reproductive Health Matters Vol. 10, No. 20, pp 38-46.

Anand, S. and Hanson, K. (1998) "DALYs: Efficiency vs. Equity" World Development Vol. 26, No. 2, pp. 301-310.

Bangser, M., Gumodoka, B., Berege, Z. (1999) "A Comprehensive Approach to Vesico-Vaginal Fistulae: a project in Mwanza, Tanzania" pp. 157 - 165 in Berer, M. and Ravindran, T.K.S. Safe Motherhood Initiatives: critical issues (oxford: Blackwell for Reproductive Health Matters).

Borghi, J., Hanson, K., Acquah, C.A., Ekanmien, G., Filippi, V., Ronsmans, C., Brugha, R., Browne, E., Alihonou, E. (2003) "Costs of near-miss obstetric complications for women and their families in Benin and Ghana" Health Policy and Planning 18(4): 383-390.

Burchardt, T. (2002) “Constraint and opportunity: women's employment in Britain" Paper presented at "Promoting Women's Capabilities: Examining Nussbaum's Capabilities Approach" Von Hugel Institute, St. Edmund's College, Cambridge University, 9-10 September, 2002.

Comim, F. (2001) “Operationalising Sen's Capability Approach" Paper presented at "Justice and Poverty: examining Sen's Capability Approach" Von Hugel Inst., Cambridge University, 5-7 June 2001.

Cook, R.J. (1995) "Women's International Human Rights Law: The Way Forward" pp. 3 - 36 in Cook, R.J. (Ed.) Human Rights of Women: National and International Perspectives (Philadelphia: University of Pennsylvania Press)

Cottingham and Myntti (2002) "Reproductive Health: Conceptual Mapping and Evidence" pp. 83-109 in Sen, G., George, A. and P. Ostlin (Eds.) Engendering International Health: the Challenge of Equity (London: MIT Press)

DeJong, Jocelyn (2000) "The Role and Limitations of the Cairo International Conference on Population and Development." Social Science and Medicine 51 : 941953, 2000

De Waal, Alex (1990) "A re-Assessment of Entitlement Theory in the Light of Recent Famines in Africa" Development and Change, Vol. 21, No. 3, July.

Donnay, F., Weil, L. (2004) "Obstetric Fistula: the international response" The Lancet Vol. 363, Issue 9402, pp. 71-2.

Egyptian Ministry of Health (1993) National Maternal Mortality Study

E1 Dawla, Aida Seif (2000) "Reproductive Rights of Egyptian Women: Issues for Debate" Reproductive Health Matters Vol. 8, No. 16, pp. 45-54 
Filippi, V. (1998) "Near Misses: maternal morbidity and mortality" Lancet Vol. 351, January 10. Pp. 145-146.

Freedman, L. (1999a) "Reflections on Emerging Frameworks of Health and Human Rights" in Mann, J.M., Gruskin, S., Grodin, M.A. and Annas, G.J. (1999) Health and Human Rights: A Reader (New York: Routledge).

Freedman, L. (1999b) "Censorship and Manipulation of Family Planning Information: An Issue of Human Rights and Women's Health" in Mann, J.M., Gruskin, S., Grodin, M.A. and Annas, G.J. (1999) Health and Human Rights: A Reader (New York: Routledge).

Gore, C. (1997) "Irreducibly Social Goods and the Informational Basis of Amartya Sen's Capability Approach” Journal of International Development Vol. 9, No. 2, 23550 .

Graham, W.J., and Campbell, O.M. (1992) "Maternal Health and the Measurement Trap" Social Science and Medicine, 5(8): 967-77.

Graham, W.J., Fitzmaurice, A.E., Bell, J.S. and Cairns, J.A. (2004) "The Familial Technique for Linking Maternal Death with Poverty" The Lancet, Vol. 363, January 3, pp. 23-27.

Hanson, K. (2002) "Measuring Up: Gender, Burden of Disease and Priority" pp. 313345 in Sen, G., George, A. and P. Ostlin (Eds.) Engendering International Health: the Challenge of Equity (London: MIT Press)

Harcourt, Wendy (2001) "The Capabilities Approach for Poor Women: empowerment strategies towards gender equality, health and well-being" Paper presented at "Justice and Poverty: examining Sen's Capability Approach" Von Hugel Inst., Cambridge University, 5-7 June 2001.

Hill, P. (2002) "Between Intent and Achievement in Sector-Wide Approaches: Staking Claim for Reproductive Health" Reproductive Health Matters Vol 10, No. 20, pp. $29-37$

Kabakian-Khasholian, T., Campbell, O., Shediac-Rizkallah, M. and Ghorayeb, F. (2000) "Women's experiences of maternity care: satisfaction or passivity?" Social Science and Medicine 51: 103-113.

Khattab, H., Younis, N. and Zurayk, H. (1999) Women, Reproduction, and Health in Rural Egypt: The Giza Study. Cairo: The American University of Cairo Press.

Loudon, I. (2000) "Maternal mortality in the past and its relevance to developing countries today" American journal of Clinical Nutrition, Vol. 72, No. 1, pp. 241-246.

Maine, D. (1999) "What is so special about maternal mortality?" pp. 175-182 in Berer, M. and Ravindran, T.K.S. Safe Motherhood Initiatives: critical issues (oxford: Blackwell for Reproductive Health Matters). 
Nussbaum, Martha (2000) Women and Human Development: the Capabilities Approach (Cambridge: Cambridge University Press)

Petchesky, R. and Judd, K. (1998) Negotiating Reproductive Rights: Women's Perspectives across Countries and Cultures (London: Zed Books)

Rawls, John (1973) A Theory of Justice (London: Oxford University Press)

Reidpath, D., Allotey, P.A., Kouame, A., Cummins. R. (2003) "Measuring health in a vacuum: examining the disability weight of the DALY" Health Policy and Planning 18(4): 351-356.

Robeyns, Ingrid (2002) Sen's Capability Approach and Gender Inequality” Paper presented at "Promoting Women's Capabilities: Examining Nussbaum's Capabilities Approach" Von Hugel Institute, St. Edmund's College, Cambridge University, 9-10 September, 2002.

Robeyns, Ingrid (2001) "Sen's capability approach and feminist concerns" Presented at conference "Justice and Poverty: examining Sen's Capability Approach" Von Hugel Inst., Cambridge University, 5-7 June 2001 (quoted with permission of the author).

Robeyns (2000) “An unworkable idea or a promising alternative? Sen's capability approach re-examined" (forthcoming, quoted with permission of the author)

Sadana, R. (2000) "Measuring reproductive health: review of community-based approaches to assessing morbidity" Bulletin of the World Health Organization Vol. 78 , Issue 5, pp. $640-654$

Saith, R. and Harriss-White, B. (1999) "The Gender Sensitivity of Well-being Indicators" Development and Change Vol. 30, pp. 465-497.

Sen, A.K. (1989) “Women's Survival as a Development Problem” Bulletin of American Academy of Arts and Sciences Volume 43.

Sen, A.K. (1990) "Development as Capability Expansion" in Keith Griffin and John Knight (Eds.) Human Development and the International Development Strategy for the 1990s, Macmillan.

Sen, A.K. (1992) Inequality Reexamined (Oxford: Oxford University Press)

Sen, A.K. (1993) "Capability and Well-being" pp. 30-53 in Sen and Nussbaum (1993) The Quality of Life (Oxford: Clarendon Press)

Sen, Amartya (1994a) "Population: Delusion and Reality," New York Times Review of Books, 41, 15, 62-71. 
Sen, A.K. (1994b) "Well-being, Capability and Public Policy" Giornale degli Economiste Annali de Econ, vol. 3, PT 7-9, pp. 333-347

Sen, A.K., (1999) Development as Freedom (Oxford: Oxford University Press)

Sen, A.K. (2002) “Why Health Equity?” Health Economics Vol. 11, No. 8, pp. 659 666

Sen, G.,Germain, A. and Chen, L. (1994) Population Policies Reconsidered: Health, Empowerment and Rights. (Boston: Harvard University Press)

Standing, H. (2002) "An Overview of Changing Agendas in Health Sector Reform" Reproductive Health Matters Vol. 10, No. 20, pp. 19-28.

Tsui, A., Waserheit, J.N., Jaaga, J.G. (Eds) (1997) Reproductive Health in Developing Countries (Washington, D.C.: National Academy Press)

Unterhalter, Elaine (2002) "The capabilities approach and gendered education: an examination of South African contradictions" Paper presented at "Promoting Women's Capabilities: Examining Nussbaum's Capabilities Approach" Von Hugel Institute, St. Edmund's College, Cambridge University, 9-10 September, 2002.

World Bank (1993) Investing in health. World Development Report. Washington, D.C.

Zurayk, H., Khattab, H., Younis, N., Khalil, K., Farag, A-M. (1996) “A Holistic Reproductive Health Approach in Developing Countries: Necessity and Feasibility" Health Transition Review, 6: 92-94. 